\title{
Gestor do doente ou um médico de família disponível
}

Paula Broeiro*

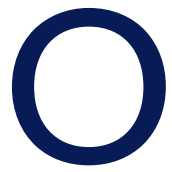

gestor do doente, como uma nova profissão na saúde, é um termo que se tem ouvido através da comunicação social e das redes sociais. Importa clarificar o que se entende por gestor do doente e perceber alguma da indignação manifesta num contexto de crise e restrição orçamental. Nos programas de Gestão Integrada da Doença (GID), o gestor do doente tem como objetivo centrar os cuidados no paciente e na família, coordenando cuidados, facilitando o acesso e a comunicação entre prestadores, monitorizando o cumprimento dos planos de cuidados, proporcionando educação para a saúde e incentivando a capacitação dos pacientes. ${ }^{1}$ Não se entende em que difere do perfil de competências do Médico de Família internacionalmente aceite. ${ }^{2}$ Existindo já, no Serviço Nacional de Saúde (SNS), profissionais com o perfil, porquê criar outra figura e não assegurar as condições para o exercício em pleno da Medicina Geral e Familiar (MGF), incluindo horário protegido para as tarefas de coordenação e gestão, bem como tempos de consulta que permitam uma abordagem holística e integral da pessoa e/ou família que adoece?

A GID é um termo em moda que surgiu, na década de 90 do século passado, como resposta à carga económica e social decorrente do cuidado às doenças crónicas e à necessidade de melhorar a qualidade dos cuidados. $^{3-4}$ Políticos e indústria das tecnologias da informação têm sido dos maiores entusiastas da GID. ${ }^{3}$ A Kaiser Permanente, um dos seus impulsionadores, tem programas baseados em Cuidados de Saúde Primários (CSP), desconhecendo-se ainda o seu real impacto sobre os pacientes, médicos e o próprio sistema de saúde. ${ }^{3}$ A GID é complexa, principalmente em pacientes com multimorbilidade, dependendo o seu sucesso de médicos bem treinados que trabalhem em equipa multidisciplinar. As decisões de gestão individualizada de cada paciente e família, numa continuidade da relação e de cuidado são, muitas vezes, difíceis. ${ }^{3}$ A multimorbi-

*Directora da Revista Portuguesa de Medicina Geral e Familiar lidade, cada vez mais frequente, ${ }^{5-7}$ necessita de uma abordagem holística que avalie o impacto sobre a funcionalidade e a qualidade de vida, a gestão integrada de factores comuns de risco, planeamento e coordenação entre vários prestadores de cuidados e as condições que levam em conta as preocupações do paciente. ${ }^{5,8-9} \mathrm{~A}$ abordagem holística da multimorbilidade contraria a lógica da GID e das Normas de Orientação Clínica (NOC), orientadas para um único problema. As NOC e os indicadores delas decorrentes deveriam ser revistos para doentes com multimorbilidade, que requerem abordagem e indicadores orientados para o paciente (ex., qualidade de vida, funcionalidade). Em Portugal, como noutros países, têm que se rever, para este grupo de pacientes, os atuais modelos baseados numa única doença e deveriam ser substituídos por outros mais integrados, nos quais o impacto de todas as patologias do paciente sobre a sua qualidade de vida deve ser considerado. ${ }^{5}$ As mudanças que têm vindo a ser implementadas no SNS parecem ter subjacente o modelo de GID, não se entendendo se o que se pretende é uma verdadeira reforma do SNS.

Porter, em 2009, a propósito da reforma da saúde nos Estados Unidos da América (EUA), afirmava que a urgência estava em definir uma estratégia nacional clara que estabelecesse uma visão abrangente do tipo de sistema de saúde que desejavam e o caminho a seguir para o atingir. ${ }^{10}$ A questão era se seria possível passar duma abordagem reativa e fragmentada para uma verdadeira estratégia nacional de saúde centrada em valor. ${ }^{10}$

As reformas dos cuidados de saúde deveriam centrar-se em melhorar o valor de saúde e cuidados de saúde, para os pacientes, como indicador ético, ${ }^{11} \mathrm{em}$ diminuir a complexidade dos sistemas e não se orientar pela oferta, antes pela procura (necessidade). ${ }^{7}$

O sucesso das reformas dependerá do alinhamento dos interesses dos pacientes e dos profissionais de saúde, incluindo os médicos, assim como dos sistemas de saúde. Se os pacientes forem valorizados, eles serão 
capazes de se envolver na autogestão de recursos. ${ }^{11}$

O estudo intitulado What keeps family physicians busy in Portugal? A multicentre observational study of work other than direct patient contacts teve, entre outros objetivos, o de quantificar o tempo consumido, pelos Médicos de Família Portugueses, noutras tarefas que não o contacto direto com o paciente. ${ }^{12}$ Neste estudo de Granja et al, o tempo médio gasto noutras tarefas, que não o contacto direto com o paciente, foi superior a 11 horas semanais, valor inferior ao de outros estudos realizados nos EUA. ${ }^{12}$ Metade do tempo gasto nestas tarefas, sem contacto direto com o paciente, esteve diretamente relacionado com atividade assistencial, permitindo garantir a acessibilidade, a continuidade e a coordenação de cuidados. ${ }^{12}$

Olhando para a realidade Portuguesa, existe um paradoxo preocupante entre a necessidade de tempo protegido para tarefas que trazem melhoria de eficiência assistencial, bem como possibilidade de reflexão sobre a prática e investigação e a prioridade dada à atividade assistencial direta, com restrição temporal (quantidade vs qualidade) definida pelos decisores. Gastando os médicos, em média, 11 horas semanais e estando a ser reduzido esse tempo protegido ${ }^{12}$ deixar-se-ão de realizar essas tarefas de retaguarda que trazem ganhos de eficiência ou serão efetuadas em tempo pessoal? Como solução, cria-se a figura do gestor do doente, sem se saber, dos próprios doentes, se preferem ter mais uma pessoa a interferir na sua vida e na sua saúde ou ter o seu médico de família mais disponível, redimensionando as listas de utentes e as definições do horário semanal?

Na sequência da 14th WONCA European Conferen$c e$, realizada em Lisboa e no confronto com outras realidades, verificou-se que, enquanto MGF, não estamos aquém do que se faz noutros países, antes pelo contrário. A diferença existente é o facto de não termos ainda criado evidência por não termos investigado ou publicado. O que reforça a afirmação de Granja et al, de que a investigação é essencial ao desenvolvimento da MGF enquanto disciplina académica e científica. ${ }^{12}$

Estamos no caminho inverso dos EUA, isto é, tínhamos um SNS universal e um sistema residualmente misto e evoluímos para um sistema fragmentado, implementando medidas avulsas, sem um verdadeiro pensamento holístico integrado. Os decisores têm dado maior importância aos sistemas de informação (mais ao software que ao hardware) que à essência da atividade médica e às pessoas que adoecem. No entanto, apesar da prioridade dada aos sistemas de informação, estamos longe de uma verdadeira integração da informação entre níveis de cuidados e dentro dos CSP. Outra das barreiras à eficiência é a não concluída integração de cuidados, em permanente mudança (ex. Carta Hospitalar),${ }^{13}$ sem avaliação do impacto na saúde, na sociedade e na economia. Perante a complexidade criada pela própria (des) organização do sistema Português, cria-se, como uma das soluções, uma nova profissão, o gestor do doente. ${ }^{7}$ Talvez possa fazer sentido nos EUA, que tem uma estrutura de CSP diferente da Portuguesa. Questiona-se porque continuamos com uma baixa autoestima, enquanto povo e profissionais, e aceitamos importações organizacionais não validadas para o contexto português (cultural e economicamente).

Um dos motores das reflexões de Porter sobre eficiência foi o reconhecimento de que países com sistemas universais têm menores despesas com cuidados de saúde do que os EUA. ${ }^{10}$ Enquanto os EUA repensam o seu sistema de saúde, em Portugal importam-se medidas avulsas, como a iniciativa do gestor do doente. Em Portugal, a pretexto da falta de Médicos de Família e da crise, impõem-se aos Médicos de Família medidas normativas que tendem à descaracterização da essência do ser médico e a caminhar no sentido inverso do considerado desejável.

O que precisamos, na doença crónica, é de decisores que:

1. Valorizem as pessoas que adoecem e os seus profissionais;

2. Identifiquem as virtudes do SNS Português;

3. Implementem medidas depois de avaliadas as existentes;

4. Se orientem pela procura e não pela oferta;

5. Não importem medidas parcelares de modelos dispendiosos (ex., gestor do doente) sem prévia avaliação do seu custo-efetividade;

6. Desincentivem, nos CSP, modelos orientados para a doença, dificilmente aplicáveis em situações de multimorbilidade;

7. Pensem simples e integrem realmente cuidados e informação;

8. Por fim, criem condições para que os Médicos de Família o sejam em pleno. 


\section{REFERÊNCIAS BIBLIOGRÁFICAS}

1. Taylor EF, Meyers DS. Enhancing the primary care team to provide redesigned care: the roles of practice facilitators and care managers. Ann Fam Med. 2013;11(1):80-3.

2. EURACT. A definição europeia de medicina geral e familiar: clínica ge$\mathrm{ral} /$ medicina familiar. EURACT; 2005. Available from: http://www.apmgf.pt/ficheiros/Definicao_MGF-EURACT_2005.pdf. Portuguese

3. Geyman JP. Disease management: panacea, another false hope, or something in between? Ann Fam Med. 2007;5(3):257-60.

4. Escoval A, Coelho A, Diniz JA, Rodrigues M, Moreira F, Espiga P. Gestão integrada da doença: uma abordagem experimental de gestão em saúde [Integrated disease management: na experimental approach in health management]. Rev Port Saude Publica. 2010;9:105-16. Portuguese

5. Harris MF, Dennis S, Pillay M. Multimorbidity: negotiating priorities and making progress. Aust Fam Physician. 2013;42(12):850-4.

6. Fortin M, Stewart M, Poitras ME, Almirall J, Maddocks H. A systematic review of prevalence studies on multimorbidity: toward a more uniform methodology. Ann Fam Med. 2012. 2012;10(2):142-51.
7. Lopes M, Mendes F, Escoval A, Agostinho M, Vieira C, Vieira I, et al. Cuidados continuados integrados em Portugal: analisando o presente, perspectivando o futuro. Lisboa: Ministério da Saúde; 2010. Portuguese

8. Broeiro P, Ramos V, Barroso R. O mapa de problemas: um instrumento para lidar com a morbilidade multipla. Rev Port Clin Geral. 2007;23(2):209-15. Portuguese

9. Roland M, Paddison C. Better management of patients with multimorbidity. BMJ. 2013;346:f2510.

10. Porter ME. A strategy for health care reform: toward a value-based system. N Eng J Med. 2009;361(2):109-12.

11. Porter ME, Teisberg EO. How physicians can change the future of health care. JAMA. 2007;297(10):1103-11.

12. Granja M, Ponte C, Cavadas LF. What keeps family physicians busy in Portugal? A multicentre observational study of work other than direct patient contacts. BMJ Open. 2014;4:e005026.

13. Portaria $n^{\circ} 82 / 2014$, de 10 de abril. Diário da República. $1^{\text {a }}$ série(71).

\section{ENDEREÇO PARA CORRESPONDÊNCIA}

director@rpcg.apmcg.pt 